\title{
SISTEM INFORMASI ADMINISTRASI KEPENDUDUKAN (STUDI KASUS : DESA PARSAORAN AJIBATA KECAMATAN AJIBATA KABUPATEN TOBA SAMOSIR)
}

\author{
Novendra Adisaputra Sinaga ${ }^{1)}$, Sarida Sirait ${ }^{2)}$ \\ Komputerisasi Akuntansi, Politeknik Bisnis Indonesia \\ Email : mrnoven@gmail.com ${ }^{1}$, saridasrt@gmail.com ${ }^{2}$
}

\begin{abstract}
Parsaoran Sibisa Village, Ajibata is the village with the highest population density with a fairly high population movement in Ajibata Subdistrict, Toba Samosir Regency. At present the administrative system and population data activities are used by the filing method. Filing method is done by recording population data in population archive books, this method is less effective and efficient when there is a complex process of finding population data and population data reports. From these data it can be concluded that the problem in Parsaoran Ajibata Village is the lack of orderly administration of population so that population services are less effective and efficient. Therefore, the writer tries to offer a solution to build Population Administration Information System as Supporting Population Administration Order in Parsaoran Sibisa Village, Ajibata District, Toba Samosir Regency. Through assistance and training to the Village Government it will increase the knowledge and understanding of the importance of using Information Systems in terms of efficiency and effectiveness so that the Population Database in the Pisaoran Sibisa Village, Ajibata District is complete, accurate, and up to date.
\end{abstract}

Keywords: Systems, Information Systems, Administration, Population

\section{PENDAhuluan}

Desa Parsaoran Ajibata adalah salah satu Pemerintahan yang berada di Kecamatan Ajibata Kabupaten Toba Samosir. Berdasarkan data BPS Toba Samosir Tahun 2017 (https://tobasamosirkab.bps.go.id/publication)

di Kecamatan Ajibata, Desa Parsaoran Ajibata adalah desa dengan jumlah penduduk terbesar berkisar 1.545

Saat ini Pengolahan data penduduk yang sedang berjalan di Desa Parsaoran Ajibata masih menggunkan pembukuan secara manual yaitu data penduduk masih dicatat dalam buku induk kependudukan yang disediakan oleh Desa dan cara tersebut belum dapat diakses secara komputerisasi.(Sumber wawancara dengan Pemerintah Desa Parsaoran Ajibata 13 Agustus 2018).

Dengan Sistem yang masih manual banyak sekali ditemukan masalah diantaranya kesulitan mendata Penduduk Lahir, mati, pindah dan datang. Ditambah lagi masalah pembuatan Surat Keterangan yang menyebabkan banyaknya terjadi kesalahan. Masalah yang lain juga ditemukan berupa keterlambatan informasi yang dibutuhkan, proses pengarsipan yang tidak efisien, kemungkinan kesalahan penyajian data yang dilakukan oleh manusia atau Pemerintah Desa itu sendiri. Selain itu Pemerintah Desa juga kesulitan mendapatkan informasi seputar Warga apabila Data Pendudukan diperlukan informasi. (Sumber wawancara dengan Pemerintah Desa Parsaoran Ajibata 13 Agustus 2018).

Berdasarkan latar belakang diatas, penulis ingin membuat sebuah penelitian dalam membangun sebuah Sistem Informasi Administrasi Kependudukan (Studi Kasus : Desa Parsaoran Ajibata Kecamatan Ajibata Kabupaten Toba Samosir).

\section{METODE PENELITIAN}

\subsection{Administrasi Kependudukan}

Administrasi kependudukan adalah rangkaian kegiatan penataan dan penertiban dalam penerbitan dokumen dan data kependudukan melalui pendaftaran penduduk dan catatan sipil, pengelolaan informasi administrasi kependudukan serta pendayagunaan hasilnya untuk pelayanan publik dan pembangunan sektor lain (Vide Pasal 1 UU No. 23 Thn 2006). Hakikat administrasi kependuduka adalah pengakuan negara terhadap hak public (domisili, pindahdatang) dan hak sipil penduduk di bidang administrasi kependudukan. 


\subsection{Sistem}

Suatu sistem adalah suatu jaringan kerja dari prosedur-prosedur yang saling berhubungan, berkumpul bersama-sama untuk melakukan suatu kegiatan atau untuk menyelesaikan suatu sasaran tertentu [1].

Sistem adalah sekumpulan elemen yang saling terkait atau terpadu yang dimaksudkan untuk mencapai suatu tujuan [2].

Elemen-elemen yang membentuk sebuah sistem, yaitu :

a. Tujuan (Goal)

Setiap sistem memiliki tuljuan (goal), entah hanya satu atau mungkin banyak. Tujuan inilah yang menjadi pemotivasi yang mengarahkan sistem. Tanpa tujuan, sistem menjadi tidak terarah dan tidak terkendali. Tentu saja, tujuan antara suatu sistem dengan sistem lain berbeda-beda. Begitu pula yang berlaku pada sistem informasi.

b. Masukan (Input)

Masukan (input) sistem adalah segala sesuatu yang masuk ke dalam sistem dan selanjutnya menjadi bahan untuk diproses. Masukan dapat berupa hal-hal berwujud (tampak secara fisik) maupun yang tidak tampak. Contoh masukan yang berwujud adalah bahan mentah, sedangkan contoh yang tidak berwujud adalah informasi (misalnya permintaan jasa dari pelanggan). Pada sistem informasi, masukan dapat berupa data transaksi dan data non-transaksi (misalnya, surat pemberitahuan), serta instruksi.

\section{c. Proses (Process)}

Proses (process) merupakan bagian yang melakukan perubahan atau transformasi dari masukan menjadi keluaran yang berguna, misalnya berupa informasi dan produk, tetapi juga bisa berupa hal-hal yang tidak berguna, misalnya saja sisa pembuangan atau limbah. Pada sistem informasi, proses dapat berupa suatu tindakan yang bermacam-macam.

d. Keluaran (Output)

Keluaran (output) merupakan hasil dari pemrosesan. Pada sistem informasi, keluaran bisa berupa suatu informasi, saran, cetakan laporan dan sebagainya.

$\begin{array}{ccc}\text { e.Mekanisme } & \text { Pengendalian } & \text { (Control } \\ \text { Mechanism) dan } & \text { Umpan Balik (Feed-Back) } \\ \text { Mekanisme } & \text { pengendalian } & \text { (control } \\ \text { mechanism) } & \text { diwujudkan } & \text { dengan }\end{array}$ menggunakan umpan balik (feed-back), yang mencuplik keluaran. Umpan balik berfungsi untuk mengendalikan baik masukan maupun proses. Tujuannya adalah untuk mengatur agar sistem berjalan sesuai dengan tujuan. Dalam bentuk yang sederhana, dilakukan perbandingan antara keluaran sistem dan keluaran yang dikehendaki (standar). Jika terdapat penyimpangan, akan dilakukan pengiriman masukan untuk melakukan penyesuaian terhadap proses supaya keluaran berikutnya mendekati standar. Bila penyimpangan terletak pada proses, prosesnyalah yang diperbaiki.

f. Batas (Boundary)

Batas (boundary) sistem adalah pemisah antara sistem dan daerah di luar sistem (lingkungan). Batas sistem menentukan konfigurasi, ruang lingkup, atau kemampuan sistem. Sebagai contoh, pertumbuhan sebuah toko kelontong dipengaruhi oleh pembelian oleh pelanggan, gerakan pesaing dan ketersediaan dana dari bank.

\section{g. Lingkungan}

Lingkungan adalah segala sesuatu yang berada di luar sistem. Lingkungan dapat berpengaruh terhadap operasi sistem dalam arti dapat merugikan atau menguntungkan sistem itu sendiri. Lingkungan yang merugikan tentu saja harus ditahan dan dikendalikan supaya tidak mengganggu kelangsungan operasi sistem, sedangkan lingkungan yang menguntungkan tetap harus dijaga, karena memacu terhadap kelangsungan hidup sistem. Lingkungan bagi sebuah organisasi berupa pemasok, pelanggan, pemilik, pemerintah, bank dan bahkan pesaing [2].

\subsection{Sistem Informasi}

Sistem informasi yang didefinisikan Robert A. Leitch dan K. Roscoe Davis :

"Sistem informasi adalah suatu sistem di dalam suatu organisasi yang mempertemukan kebutuhan pengolahan transaksi harian, mendukung operasi, bersifat manajerial dan kegiatan strategi dari suatu organisasi dan menyediakan pihak luar tertentu dengan laporan-laporan yang diperlukan." [1]. Menurut John Burch dan Gary Grudnitski, dalam sistem informasi terdiri dari beberapa komponen yaitu :

a. Blok masukkan (input block), meliputi metode dan media untuk menangkap data yang akan dimasukkan, dapat berupa dokumen dasar.

b. Blok model (model block), terdiri dari kombinasi prosedur, logika dan model 
matematik yang berfungsi memanipulasi data untuk keluaran tertentu.

c. Blok keluaran (output block), berupa data keluaran seperti dokumen dan informasi yang berkualitas.

d. Blok teknologi (technology block), digunakan untuk menerima masukkan, menjalankan model, menyimpan dan mengakses data, menghasilkan dan mengirimkan keluaran serta membantu pengendalian dari sistem secara keseluruhan.

e. Blok basis data (database block), merupakan kumpulan data yang berhubungan satu dengan lainnya, tersimpan diperangkat keras komputer dan perangkat lunak yang memanipulasinya.

f. Blok kendali (controls block), meliputi masalah pengendalian terhadap operasional sistem yang berfungsi mencegah dan menangani kesalahan atau kegagalan sistem [1].

\subsection{Database}

Basis data tidak hanya merupakan kumpulan file. Lebih dari itu, basis data adalah pusat sumber data yang caranya dipakai oleh banyak pemakai untuk berbagai aplikasi. Inti dari basis data adalah Data Base Management System (DBMS), yang membolehkan pembuatan, modifikasi, dan pembaharuan basis data; mendapatkan kembali data; dan membangkitkan laporan [3].

Tujuan basis data yang efektif yaitu :

a. Memastikan bahwa data dapat dipakai di antara pemakai untuk berbagai aplikasi.

b. Memelihara data baik keakuratan maupun kekonsistenannya.

c. Memastikan bahwa semua data yang diperlukan untuk aplikasi sekarang dan yang akan datang akan disediakan dengan cepat.

d. Membolehkan basis data untuk berkembang dan kebutuhan pemakai untuk berkembang.

e. Membolehkan pemakai untuk membangun pandangan personalnya tentang data tanpa memperhatikan cara data disimpan secara fisik [4].

\subsection{MySQL}

SQL (Structured Query Language) adalah bahasa yang digunakan untuk mengakses basis data yang tergolong relasional. MySQL adalah salah satu jenis database server yang sangat terkenal. Kepopulerannya disebabkan MySQL menggunakan SQL sebagai bahasa dasar untuk mengakses database-nya. Selain itu, bersifat open source (Anda tidak perlu membayar untuk menggunakannya) pada berbagai platform (kecuali untuk jenis enterprise, yang bersifat komerisal) [2].

\subsection{PHP}

PHP singkatan dari Page Hypertext Processor (Kadir, 2008). PHP merupakan bahasa script yang ditempatkan di server dan diproses diserver hasilnya dikirimkan ke klien, tempat pemakainya menggunakan browser. Kelebihan dari PHP antara lain :

a. PHP merupakan bahasa script yang tidak melakukan sebuah kompilasi dalam penggunaannya.

b. PHP dapat berjalan pada web server yag dirilis oleh Microsoft, juga pada Apache yang bersifat open source.

c. Karena sifatnya yang open source, perubahan dan perkembangan interpreter PHP lebih cepat dan mudah, karna banyakdeveloper yang siap membantu pengembangannya.

d. PHP memiliki banyak referensi sehingga sangat mudah untuk dipahami.

PHP dapat berjalan pada 3 operating system, yaitu linux, Unix dan Windows, dan juga dapat dijalankan secara runtime pada suatu console

\subsection{Metode Penelitan}

Metode yang digunakan menerapkan perancangan sistem melalui tahap-tahap Siklus Hidup Pengembangan Sistem (System Development Life Cycle - SDLC). Tahapannya

a. Tahap Komunikasi terhadap Objek Penelitian Peneliti melakukan survei dan mengumpulkan data berupa catatan administrasi secara manual di Desa Parsaoran Ajibata Kecamatan Ajibata Kabupaten Toba Samosir.

b. Tahap Perencanaan Sistem Perencanaan sistem dilakukan berdasarkan data dan permasalahan pada waktu tahap komunikasi, dengan mempertimbangkan atribut dan kebutuhan pendataan objek yang ada.

c. Tahap Analisis Sistem Tahap ini untuk menentukan kebutuhan (requirement) yang 
dimungkinkan ada di dalam Sistem Informasi Administrasi Kependudukan. Hasil dari analisis berbentuk sebuah Desain Aplikasi yang digunakan untuk mengadministrasikan informasi secara sistematis data kependudukan.

d. Tahap Pembangunan Sistem dan Implementasi Pada tahap ini aplikasi sistem informasi administrasi kependudukan disusun berdasarkan tahapan tahapannya kemudian dilakukan desain antarmuka, kode program, desain basis data, pembangunan sistem, dan tahap implementasi.

e. Tahap Uji Coba Pengujian dilakukan menggunakan pengujian black box, yaitu pengujian dengan melihat input dan output yang akan di hasilkan. Dan proses pengujian white box, yaitu pengujian dengan melihat alur uji untuk melihat kompleksitas logis dari desain yang terdapat pada sistem tersebut.

f. Tahap Evaluasi Evaluasi dilakukan menggunakan kuisioner kepada masyarakat apakah ada dampak secara signifikan terhadap pelayanan terhadap masyarakat.

\subsection{Lokasi dan Objek Penelitian}

Kegiatan penelitian dilakukan di Desa Parsaoran Ajibata Kecamatan Ajibata Kabupaten Toba Samosir Provinsi Sumatera Utara

\subsection{Metode Pengumpulan Data}

Metode pengumpulan data meliputi:

a. Metode Wawancara

Dalam penelitian ini narasumber adalah Kepala Desa Parsaoran Ajibata Kecamatan Ajibata Kabupaten Toba Samosir

b. Studi Pustaka

Dengan mempelajari buku-buk kepustakaan, jurnal ilmiah, dan informasi dari internet, serta referensi terkait mengenai segala sesuatu yang berhubungan dengan kebutuhan penelitian ini

3. HASIL DAN PEMBAHASAN

1. Form Login

Form Login aplikasi untuk mengautentikasi pengguna dari Sistem agar dapat masuk kedalam Aplikasi. Form Login aplikasi dapat dilihat pada Gambar 1.

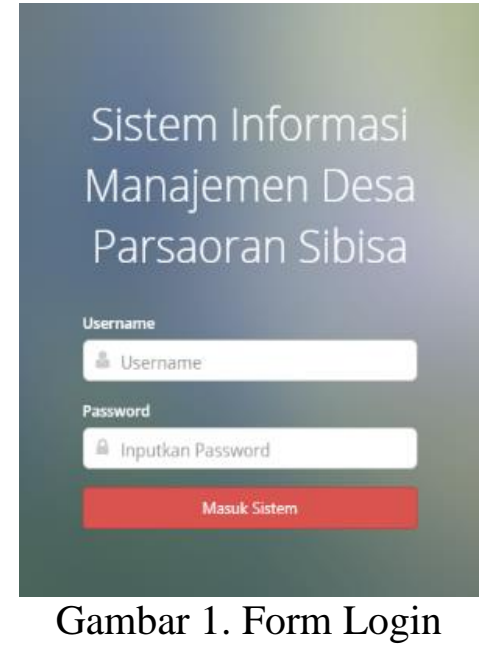

2. Menu Utama

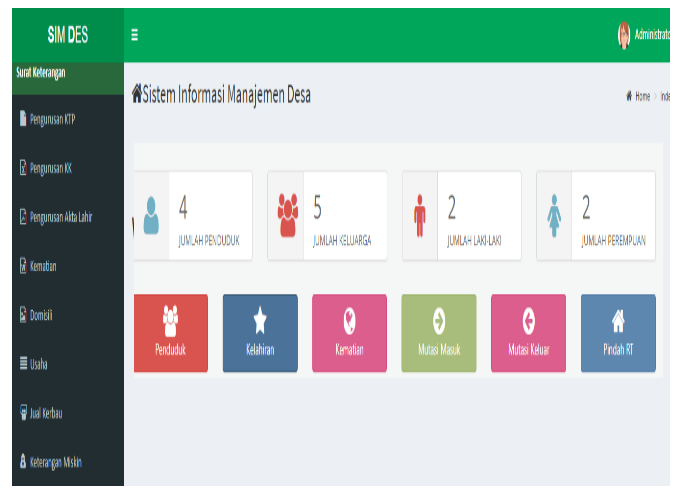

Gambar 2. Menu Utama

Gambar 2 merupakan Menu utama, ketika Login berhasil maka user akan langung masuk ke Menu Utama seperti Rancangan di atas.

\section{Form Agama}

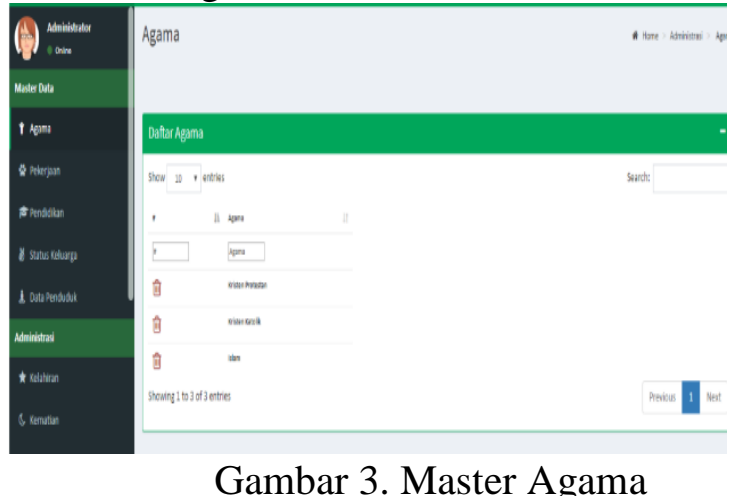

Gambar 3 merupakan Form Agama untuk memasukkan agama yang ada di Indonesia, sehingga dibuat dalam 1 Master. 


\section{Form Pekerjaan}

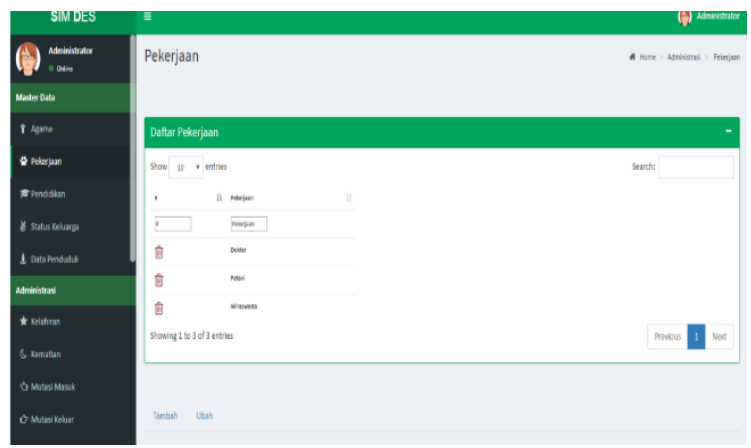

Gambar 4. Master Pekerjaan

Gambar 4 merupakan Master Pekerjaan, sebagaimana setiap list pekerjaan dari masyarakan dibuat dalam satu master.

\section{Form Pendidikan}

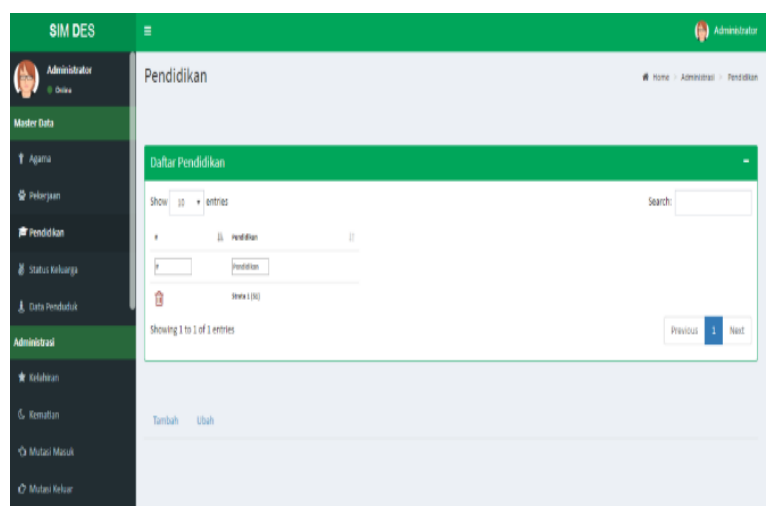

Gambar 5. Master Pendidikan

Gambar 5 merupakan Master Pendidikan, sebagaimana setiap list pendidikan dari masyarakan dibuat dalam satu master.

\section{Form Status Keluarga}

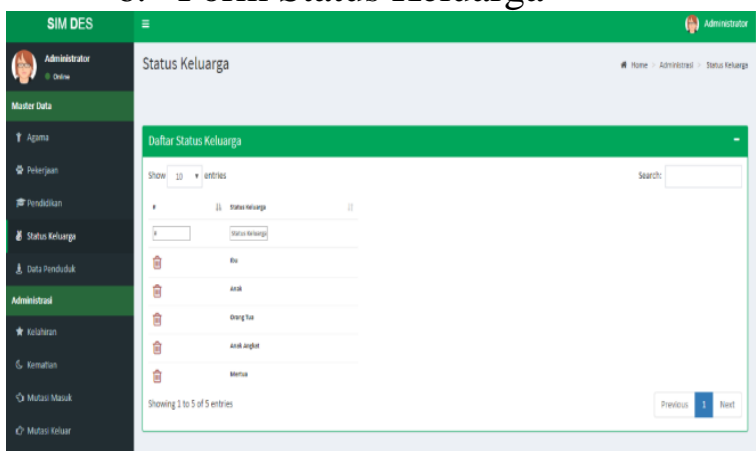

Gambar 6. Form Status Keluarga Gambar 6 merupakan Form Status Keluarga, sebagaimana setiap list Status keluarga dari masyarakan dibuat dalam satu master.
7. Data Penduduk

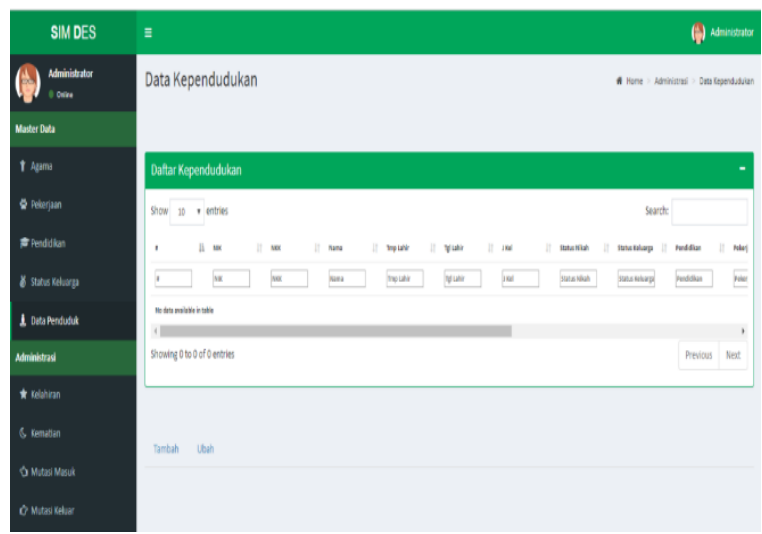

Gambar 7. Data Penduduk

Gambar 7 merupakan Form Data Penduduk, semua masyarakat di Desa Parsaoran Sibisa, semua data masing masing penduduk di input kedalam sistem sebagai Sumber Basis Data Penduduk yang terdiri dari NIK, Nomor Kartu Keluarga, Nama, Tempat Tanggal Lahir, Jenis Kelamin, Status Menikah, Status Keluarga, Alamat, Pendidikan, Pekerjaan, Nama Ibu, Nama Ayah, RT, RW, Warga Negara dan Golongongan Darah.

\section{Form Kelahiran}

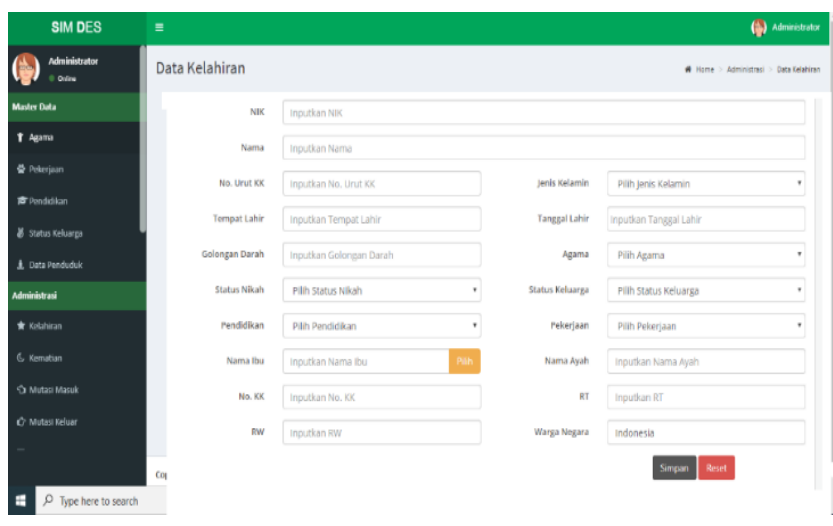

Gambar 8. Form Data Kelahiran

Gambar 8 merupakan Data Kelahiran, setiap bayi yang lahir, salah satu dari orang tua dapat langsung melaporkan kepada perangkat Desa agar identitas dari bayi langsung di input yang datanya input nya sama dengan Form Data Penduduk. 


\section{Form Kematian}

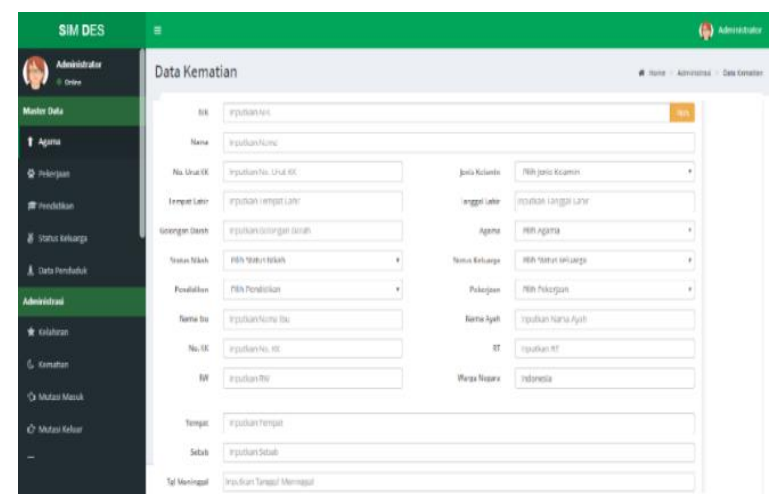

Gambar 9. Form Kematian

Gambar 9 merupakan Form Kematian yang apabila ada penduduk yang meninggal agar dapat meminta surat keterangan sudah meniggal. Syarat untuk bisa dimasukkan kedalam Form Kematian adalah penduduk yang sudah terdaftar didalam Data Kependudukan di Aplikasi tersebut dan ketika sudah berhasil maka Informasi tambahan yang harus diisi adalah Tempat Persemayaman, Tanggal Meninggal dan Keterangan kapan

\section{Mutasi Masuk}

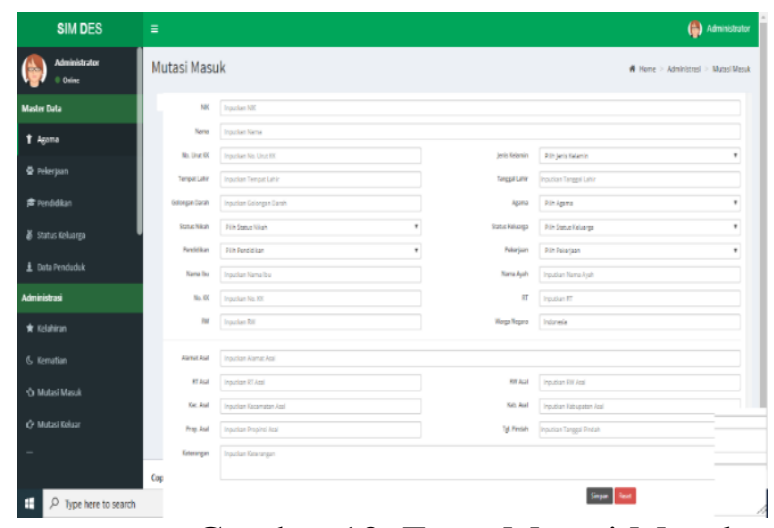

Gambar 10. Form Mutasi Masuk

Gambar 10 merupakan Form Mutasi Masuk, penduduk yang masuk ke Desa Parsaoran Sibisa harus dimasukkan kedalam Sistem. Sistem penginputan kontennya sama dengan penginputan Data Penduduk dan menambah beberapa data tambahan seperti Provinsi Asal, Kabupaten Asal, Kecamatan Asal, Alamat Asal, RT/RW Asal dan keterangan tambahan.

\section{Mutasi Keluar}

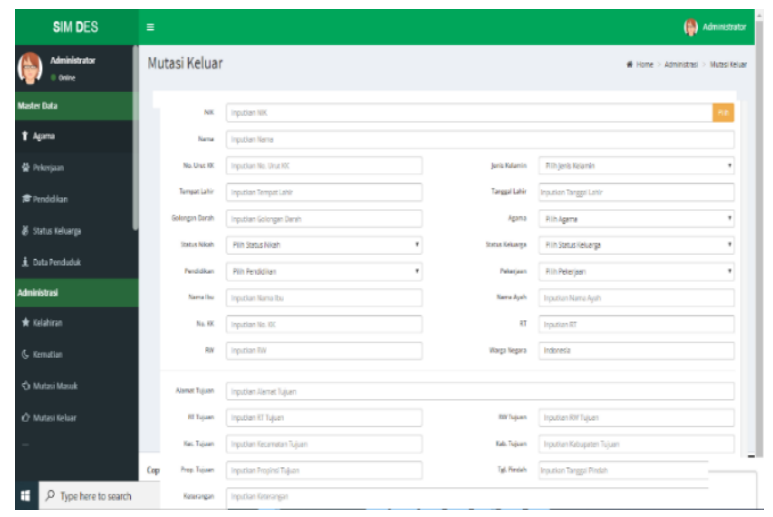

Gambar 11. Form Mutasi Keluar

Gambar 11 merupakan Form Mutasi Keluar, penduduk yang keluar ke Desa Parsaoran Sibisa harus dimasukkan kedalam Sistem. Sistem penginputan harus terdaftar dulu Datanya di Sistem yang sudah ada. Data yang di input adalah no KTP, apabila data ditemukan maka akan tampil Data Penduduk dan bisa di mutasikan keluar dengan menambah beberapa data tambahan seperti Provinsi Tujuan, Kabupaten Tujuan, Kecamatan Tujuan, Alamat Tujuan, RT/RW Tujuan dan keterangan tambahan.

\section{Form Pengurusan KTP}

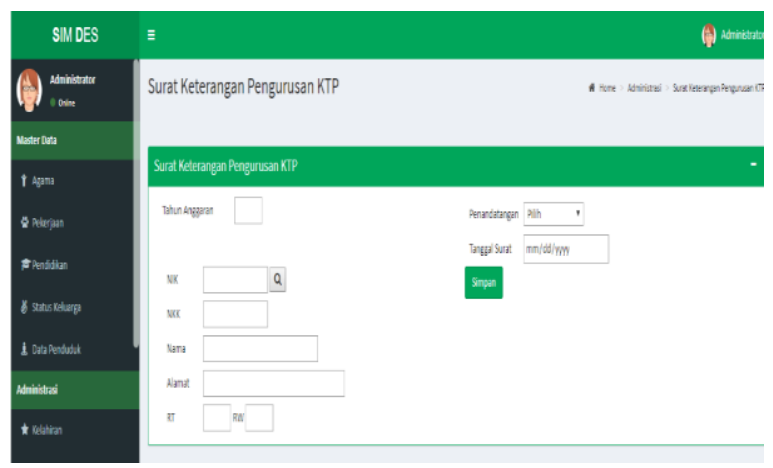

Gambar 12. Form Program Keluarga Harapan

Gambar 12 merupakan Form Program Keluarga Harapan untuk memasukkan kedalam daftar penerima Keluarga Harapan Per Tahun Anggaran dan yang berhak menerima adalah penduduk yang tetap sudah terdapaftar dalam Sistem. 


\section{Form Pengurusan KK}

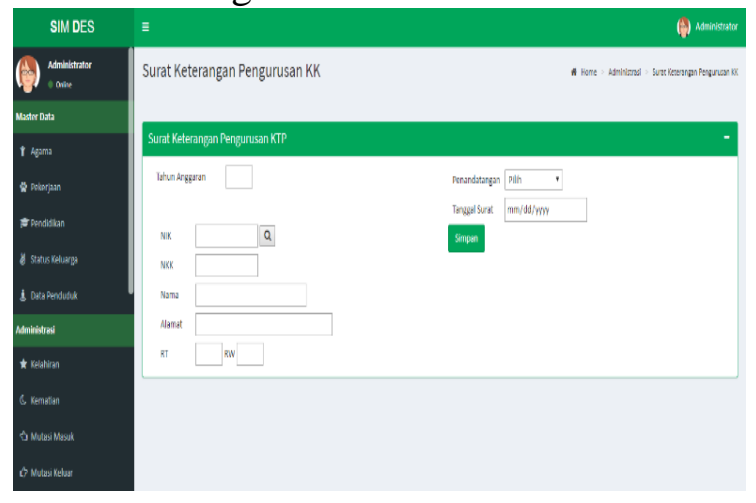

Gambar 13. Form Surat Keterangan Pengurusan KTP

Gambar 13 merupakan Form untuk membuat surat keterangan pengurusan KTP dimana identitas penduduk tetap akan dipanggil yang sudah tersimpan di dalam Database. Setelah data diinput maka sistem dapat secara langsung mencetak Surat Keterangan Pengurusan KTP.

\section{Form Pengurusan Akta Kelahiran}

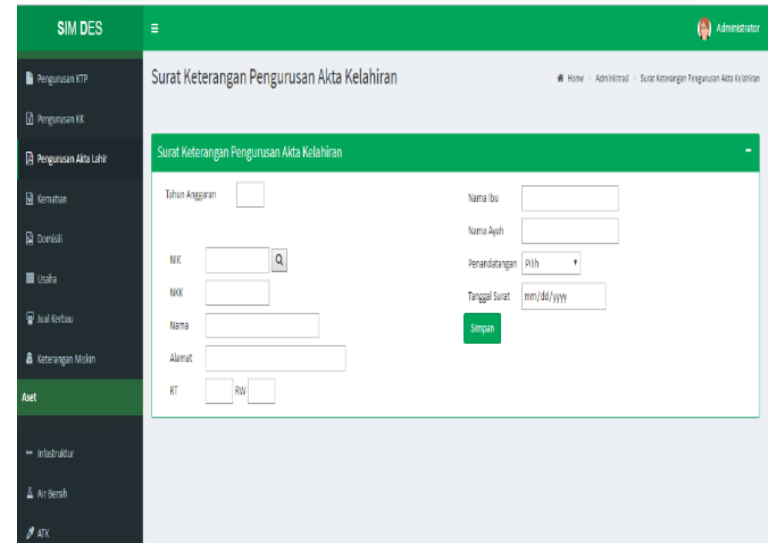

Gambar 14. Rancangan Form Surat Keterangan Pengurusan KK

Gambar 14 merupakan Rancangan Form untuk membuat surat keterangan pengurusan KK dimana identitas penduduk tetap akan dipanggil yang sudah tersimpan di dalam Database. Setelah data diinput maka sistem dapat secara langsung mencetak Surat Keterangan Pengurusan KTP.

\section{Form Surat Keterangan Kematian}

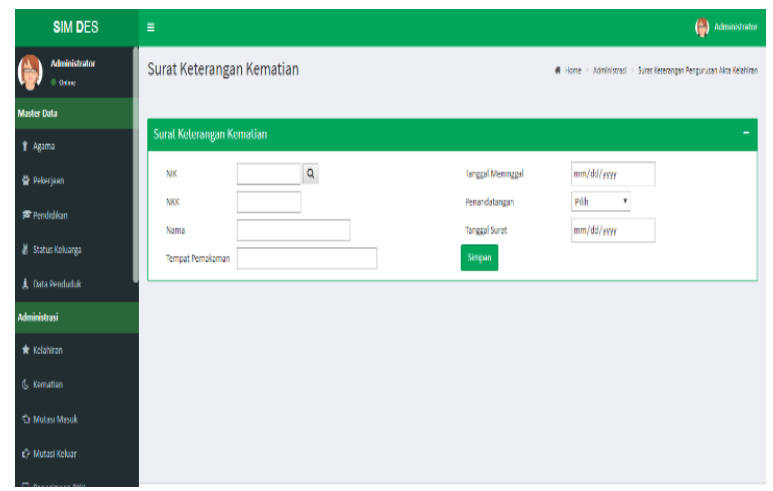

Gambar 15. Form Surat Keterangan Pengurusan Akta Lahir

Gambar 15 merupakan Rancangan Form untuk membuat surat keterangan pengurusan Akta Kelahiran dimana identitas penduduk tetap akan dipanggil yang sudah tersimpan di dalam Database dan dengan informasi tambahan sepertai Nama Ayah, Nama Ibu dan Alamat Tinggal dari Orang Tua. Setelah data diinput maka sistem dapat secara langsung mencetak Surat Keterangan Pengurusan Akta Kelahiran.

\section{KESIMPULAN}

Setelah melakukan perancangan dan implementasi Sistem Informasi Administrasi Kependudukan maka dapat diambil kesimpulan sebagai berikut :

1. Sistem Informasi Kependudukan Desa Parsaoran Ajibata Kecamatan Ajibata Kabupaten Toba Samosir sudah dilakukan secara terkomputerisasi sehingga dalam pengolahan data lebih cepat.

2. Sistem Informasi dapat mengakomodir pencarian data lebih cepat dan efisien untuk kebutuhan Pemerintah Desa.

3. Sistem Informasi juga melayani masyarakat dalam urusan surat menyurat karena semua template nya sudah tersedia dan tinggal di cetak berdasarkan surat yang diinginkan.

\section{DAFTAR PUSTAKA}

[1] Jogiyanto, H.M. 2005. Analisis \& Desain. Edisi 3. Yogyakarta : Andi

[2] Kadir, Abdul. 2014. Pengenalan Sistem Informasi. Edisi 1. Yogyakarta : Andi. 
[3] Kendall, K.E. dan J.E. Kendall. 2011. Systems Analysis and Design, Jilid 1, Edisi 8. Prentice-Hall, Inc.

[4] Kendall., K.E. dan J.E. Kendall. 2003. Analisis dan Perancangan Sistem, Alih bahasa oleh Thamir Abdul Hafedh AlHamdany. Jilid 2. Edisi 5. Jakarta : Indeks.

[5] https://tobasamosirkab.bps.go.id/publicat ion/download.html?nrbvfeve=YjI4ZjJiZ DNjOWI2YWM5M2VmOWM1MTQz \&xzmn=aHR0cHM6Ly90b2Jhc2Ftb3Np cmthYi5icHMuZ28uaWQvcHVibGljYX Rpb24vMjAxNy8wOS8xMy9iMjhmMm JkM2M5YjZhYzkzZWY5YzUxNDMva 2VjYW1hdGFuLWFqaWJhdGEtZGFsY W0tYW5na2EtMjAxNy5odG1s\&twoadf noarfeauf $=\mathrm{MjAxOCO} \mathrm{wOS} 0 \mathrm{wMSAyMzo}$ yOTo1Mw\%3D\%3D. 